\title{
Child Neurodevelopmental and Behavioural Problems are Intercorrelated and Dimensionally Distributed in the General Population
}

\author{
Henrik Anckarsäter ${ }^{*}, 1,3$, Tomas Larson ${ }^{1}$, Sara Lina Hansson ${ }^{1}$, Eva Carlström ${ }^{2}$, Ola Ståhlberg ${ }^{1,3}$, \\ Carina Gillberg ${ }^{3}$, Maria Råstam ${ }^{3}$, Christopher Gillberg ${ }^{3}$ and Paul Lichtenstein ${ }^{2}$ \\ ${ }^{I}$ Institute of Clinical Sciences, Malmö, Lund University, Sweden \\ ${ }^{2}$ Department of Medical Epidemiology and Biostatistics, Karolinska Institutet, Sweden \\ ${ }^{3}$ Institute of Neuroscience and Physiology, University of Gothenburg, Sweden
}

\begin{abstract}
The Autism - Tics, AD/HD, and other Comorbidities inventory (A-TAC) is a comprehensive interview for evaluating problems related to autism spectrum disorders (ASD), tic disorders, attention-deficit/hyperactivity disorder (AD/HD), and common comorbid conditions in children and adolescents. A-TAC telephone interviews were administered to parents of 2,957 children aged nine- or twelve-years, representing one in each twin pair included in the populationbased Child and Adolescent Twin Study in Sweden (CATSS).

A total of $16.4 \%$ were screen-positive for one or several of the targeted disorder, $1.3 \%$ for ASD and $5.6 \%$ for AD/HD. All types of problems were more common among boys, with the exception of those related to "eating habits". They were all dimensionally/continuously distributed, highly inter-correlated, and overlapped across types. They aggregated in three basic factors corresponding to externalizing/disruptiveness, socio-communicative problems, and compulsiveness.

Population-based data on problems in children thus challenge current categorical diagnostic definitions, calling for dimensional and complementary models of problem descriptions.
\end{abstract}

Keywords: Attention-deficit/hyperactivity disorder, autism spectrum, tics, comorbidity, prevalence.

\section{INTRODUCTION}

Autism spectrum disorders (ASD), attention-deficit/ hyperactivity disorder ( $\mathrm{AD} / \mathrm{HD})$, and tic disorders affect several per cent of all school-age children [1-3]. "Broader phenotypes" that overlap with personality variants have been described in relatives [4], and the overlap across these disorders is considerable [5-7]. These problem types are also found more often than expected by chance in obsessive compulsive disorder (OCD) [8], eating disorders [9], conduct disorder (CD), oppositional defiant disorder (ODD) [10], and learning disorders [11].

Disorders in this field have usually been studied as categorical disorders. This may not be an optimal approach. First, the diagnostic definitions may not correspond to real categories. A taxonomic distribution has never been empirically demonstrated for any of the major child and adolescent psychiatric disorders. Second, disorders rarely exist in "pure" forms, i.e. without co-existing symptoms from other diagnostic categories or even fully developed concomitant disorders [12-14]. It may, in effect, be more consistent with the scientific literature to regard "conditions" fitting diagnostic criteria for these disorders as expressing the lowermost extremes of normally distributed neuropsychological abilities in the areas of empathy, attention, and impulse control.

\footnotetext{
*Address correspondence to this author at Forensic Psychiatry, Lillhagsparken 3, 42250 Hisings Backa, Sweden; Tel: +46-31 343 7378;

E-mail: henrik.anckarsater@neuro.gu.se
}

In turn, such underlying abilities may be related to specific or broad aspects of brain development, which would mean that a high degree of "comorbidity" and instability would have to be expected at the diagnostic level.

The Autism - Tics, AD/HD, and other Comorbidities inventory (A-TAC) is a new parent screening tool, validated as a telephone interview screening device for $\mathrm{ASD}, \mathrm{AD} / \mathrm{HD}$, tic disorders, developmental coordination disorder (DCD), and learning disorder [15]. It is used here to present data on prevalence rates, distributions of problems, and patterns of associations between problem types in a population-based group of school-aged children.

\section{METHODS}

\section{Subjects}

Parents of all Swedish nine- and twelve-year-old twins were traced through the Swedish Twin Registry and contacted for interviews over the phone as part of the Child and Adolescent Twin Study in Sweden (CATSS) [16]. The reason for choosing this age group was that most of the major child psychiatric problem constellations have been established by then, whereas the complex psychosocial problems associated with puberty have not yet emerged.

The analyses presented in this report are based on 2,957 consecutive children ( 744 boys and 655 girls aged nine years, 806 boys and 752 girls aged twelve years), representing $81 \%$ of eligible individuals. All subjects were the first of each twin pair to be assessed by the interviewers: 1,946 were 
the first-born in the pair, 999 were the second-born, while information on birth order is missing in twelve cases. Children from both monozygotic and dizygotic (same-sex and different-sex) pairs were included. Interviewers from a professional company, "Intervjubolaget", carried out the interviews after a brief introduction in child and adolescent psychiatry and twin research.

To assess possible confounding factors, we compared prevalences for all types of problems by Fischer's exact tests between 1. subjects for whom the mother $v s$ the father answered the interview, 2. subjects from monozygotic $v s$ dizygotic pairs, and 3. nine- vs twelve-year-old subjects. Given the high number of subjects, it was assumed that the statistical power is sufficient to detect meaningful differences between these groups even after Bonferroni corrections of pvalues, i.e. multiplication with 15 for 13 modules and 2 diagnostic combinations (ASD and AD/HD, for details on the assessed definitions, see below under Methods). The mother was interviewed in 2,571 cases, the father in 369, and another member of the family in 17 instances. There was a general tendency towards lower ratings from fathers as compared to mothers, but no significant prevalence difference. Nor did children from monozygotic vs dizogotic pairs, or nine- $v s$ twelve-year-old children differ significantly for prevalence in any of the assessed definitions (detailed data from the analyses of possible confounders are available from the authors upon request).

\section{A-TAC Interviews}

The A-TAC is a comprehensive parent interview focusing on child ASD and associated conditions. It has been validated as a telephone interview (performed by lay persons) and designed to provide good screening properties for identifying significant problems/diagnostic categories as well as dimensional ratings of problems with a view to advancing both epidemiological and genetic research beyond current categorical conceptualisations of disorders.

The A-TAC initially consisted of items that cover the DSM-IV criteria for ASD, AD/HD, tic disorders, learning disorder, and DCD almost verbatim, with some items included from other established instruments/diagnostic algorithms, such as the Asperger Syndrome Diagnostic Interview [17]. The content validity of the items is supported by their close relation to these established criteria and by the authors' clinical expertise in the field. In a validation study based on telephone interviews with 111 parents of clinically diagnosed children and healthy controls, the A-TAC had "excellent" screening properties for AD/HD and ASD, and "good" screening properties for learning disorder, DCD, and tic disorders. Inter-rater and test-retest reliability coefficients were good-excellent (intra-class coefficients ranging from 0.97 to 1.0 , and from 0.77 to 0.97 , respectively), with the exception of eating problems at 0.57 [15]. With the aim of improving specificity, more items have subsequently been added based on the clinical literature, the Five To Fifteen questionnaire (FTF) [18], and our own clinical experience. Items tapping into DSM-IV-defined criteria for other disorders that have been shown to overlap with ASD, such as anorexia nervosa, $\mathrm{OCD}$, and $\mathrm{ODD} / \mathrm{CD}$, have also been added, organized in modules based on theoretical and psychometric considerations, as detailed in documents available from the web-site of the Swedish Child Neuropsychiatry Science Foundation (http://www.childnps.se). Items assessing whether reported problems or other behavioural features have caused significant dysfunctions in important areas and/or a significant level of personal suffering were added to each module. Response categories are "no" (0), "yes, to some extent" (0.5), and "yes" (1.0). For the analyses presented here, scores based on the algorithms of the preliminary validation were calculated. The score for a module is counted as "missing" if three or more items in the module were endorsed as "do not know" or "do not want to respond". Finally, for each symptom/problem module endorsed, the age of onset and persistence/age of remission were documented.

After a pilot group had been screened, we established "gate" questions that were asked to all parents, followed by questions that were asked only if one or more of the "gate" questions were affirmed. The "gate" questions were selected based on clinical relevance and ability to identify subjects for whom significant dysfunction and/or personal suffering was reported. They included all validated DSM-based items for ASD, AD/HD, and tic disorders. For further information on the instrument, including the final versions of the instrument in Swedish, English, French, and Spanish (currently for the ASD modules only), psychometric considerations during its development, and details of the "gate" structure, see the web-site referenced above. A new clinical validation, including algorithms for both screening and identification of caseness, is currently submitted for publication by Larson and coworkers.

Interviewers followed a computerized version of the A$\mathrm{TAC}$, and responses were entered directly into a database. Interviewers were instructed to ask all questions in a lifetime frame, and parents were repeatedly reminded that they should answer all questions taking a lifetime perspective into account and compare the child to his/her peers.

Scores based on the validated items and those that reflect the DSM-IV criteria were calculated for each module. Scores from the two $\mathrm{AD} / \mathrm{HD}$ modules (concentration/attention and impulsiveness/activity) and the three ASD modules (social interaction, language, flexibility) were also collapsed for assessment of these two diagnostic categories. A child was considered screen-positive for a diagnostic category if the score corresponded to the validated cut-offs for ASD $(\geq 4.5$ on the DSM-IV-related items in social interaction, communication/ language, and behavioural flexibility, $\mathrm{AD} / \mathrm{HD}(\geq 8$ on the DSM-IV related items in attention or impulsiveness), tic disorders $(\geq 2)$, learning disorder $(\geq 3.5)$ or DCD $(\geq 1.5)$ [15]. Further, in the individual modules that form $\mathrm{AD} / \mathrm{HD}$ and ASD, the cut-offs from the DSM-IV were used (i.e. 6 or more for concentration and impulsiveness, 2 for social interaction, and 1 for language and flexibility, respectively. The same principle was used for the remaining modules where no previous validation had been completed (e.g. eating disorders or conduct disorder). This paper thus reports only on modules for which a cut-off score has been possible to iden- 
tify, either through the preliminary validation or from the DSM-IV. Modules and cut-off scores applied are listed in Table 1.

\section{Statistical Methods}

Prevalence differences between groups were tested with Fischer's exact tests. All p-values are two-tailed, and provided in the Table without correction for multiple comparisons, which is, however, easily attained by multiplication of individual $\mathrm{p}$-values by 15 as described above under Subjects for the analyses of possible confounders. Significant probabilities were defined as $p \leq 0.05$. Correlations were calculated as nonparametric Spearman rank correlations as distributions of ATAC scores were skewed. The factor analysis was based on a principal axis factor analysis with a varimax rotation. The number of factors that were retained was based on the standard scree plot and eigenvalue $(>1)$ criteria. Statistical analyses were performed in the SAS 9.1 or the SPSS 12.0.

\section{Ethical Considerations}

All informants consented to the study after written and oral information. Analyses were performed on anonymized data files. The study protocol accorded with the Helsinki declaration and was approved by the ethical review board of Karolinska Institutet.

\section{RESULTS}

No significant problems corresponding to the screening algorithms, i.e. scores below the defined cut-offs in all modules, were reported in $83.6 \%$ of the children.

A total of 39 subjects $(1.3 \%)$ were screen-positive for ASD. Corresponding proportions were $5.6 \%$ for $\mathrm{AD} / \mathrm{HD}$, $1.9 \%$ for tic disorders, $7.1 \%$ for learning disorders, and $4.5 \%$ for DCD (Table 1). A total of $12.2 \%$ were screen-positive for one or more of $\mathrm{ASD}, \mathrm{AD} / \mathrm{HD}$, tic disorders, or learning disorders.

According to Fischer's exact tests, prevalences were higher among boys than girls for all problem types except eating habits (Table 1).

Median ages at onset for various problem types are shown in the last column of Table 1. Motor dyscoordination, hyperactivity, and problems with communication and social interaction were the first problem types to be detected, in most cases before three to four years of age, followed by all other problem types, which became apparent around school start at six to seven years of age (with the exception of eating problems).

There was no sign of bimodal distribution in any of the modules, as shown in Table $\mathbf{2}$.

\section{Overlap Between Problem Types}

Percentages of overlap across the diagnostic categories, and correlation coefficients between scores, are shown in Table 3. A factor-analysis with a varimax rotation showed a three-factor structure (Table 4). The three factors accounted for $66.5 \%$ of the variance. They roughly corresponded to one factor for externalizing behaviours, one factor for problems with social interaction, communication, learning, and motor control, and one factor for compulsiveness or fixations. An oblique rotation (promax) gave the same pattern (data not shown).

\section{CONCLUSIONS}

In this general population cohort, results from parent telephone interviews showed relatively high prevalence rates

Table 1. The Proportion of Children Identified as Screen-Positive

\begin{tabular}{|c|c|c|c|c|c|}
\hline Modules & $\begin{array}{l}\text { Cut-Off According to Valida- } \\
\text { tion (V) or DSM-IV (D) }\end{array}$ & $\begin{array}{l}\text { Prevalence of } \\
\text { Screen-Positive } \\
\text { Children }\end{array}$ & $\begin{array}{l}\text { Proportion } \\
\text { Boys:Girls }\end{array}$ & $\begin{array}{l}\text { P Value for Difference Boys:Girls } \\
\text { (Fischer's Exact Tests) }\end{array}$ & $\begin{array}{r}\text { Median } \\
\text { Age at } \\
\text { Onset }\end{array}$ \\
\hline Language & $1(\mathrm{D})$ & $9.2 \%$ & $2.2: 1$ & $\leq 0.001$ & 3.5 \\
\hline Social interaction & $2(\mathrm{D})$ & $1.2 \%$ & $2.6: 1$ & $\leq 0.010$ & 3.0 \\
\hline Tics & $2(\mathrm{~V})$ & $1.9 \%$ & $3.3: 1$ & $\leq 0.001$ & 6.0 \\
\hline AD/HD combined & $8(\mathrm{~V})$ & $5.6 \%$ & $2.3: 1$ & $\leq 0.001$ & \\
\hline Concentration/ attention & $6(\mathrm{D})$ & $4.0 \%$ & $1.6: 1$ & $\leq 0.011$ & 5.5 \\
\hline Impulsiveness/activity & $6(\mathrm{D})$ & $2.0 \%$ & $2.4: 1$ & $\leq 0.002$ & 3.0 \\
\hline Eating habits & $3(\mathrm{D})$ & $0.1 \%$ & $0.4: 1$ & $\leq 0.608$ & 10.5 \\
\hline Separations & $3(\mathrm{D})$ & $0.9 \%$ & $1.9: 1$ & $\leq 0.158$ & 5.5 \\
\hline Defiance & $4(\mathrm{D})$ & $2.4 \%$ & $1.9: 1$ & $\leq 0.015$ & 7.0 \\
\hline Conduct & $3(\mathrm{D})$ & $0.3 \%$ & $1.3: 1$ & $\leq 0.757$ & 6.0 \\
\hline
\end{tabular}


Table 2. The Proportion (\%) of Individuals with Number of Problems in Each Module (n=2957)

\begin{tabular}{|c|c|c|c|c|c|c|c|c|c|c|c|c|c|c|}
\hline Autism spectrum (12) & 65.3 & 14.6 & 10.0 & 3.2 & 2.3 & 1.5 & 1.0 & 0.5 & 0.3 & 0.3 & 0.4 & 0.3 & 0.1 & 0.2 \\
\hline Social interaction (4) & 90.4 & 5.4 & 2.5 & 0.5 & 0.5 & 0.4 & 0.1 & 0.0 & 0.1 & & & & & \\
\hline Flexibility (4) & 78.5 & 11.8 & 5.8 & 1.5 & 1.5 & 0.4 & 0.3 & 0.1 & 0.1 & & & & & \\
\hline AD/HD (18) & 39.0 & 10.9 & 8.5 & 6.5 & 5.3 & 4.6 & 3.3 & 3.3 & 2.4 & 4.8 & 3.4 & 1.7 & 1.5 & $5.0^{1}$ \\
\hline Concentration/Attention (9) & 51.2 & 11.8 & 8.0 & 6.3 & 4.6 & 3.2 & 3.1 & 2.3 & 1.7 & 3.1 & 1.8 & 1.3 & 1.0 & 0.8 \\
\hline Impulsiveness/Activity (9) & 55.7 & 12.0 & 9.3 & 4.9 & 4.3 & 3.7 & 2.4 & 1.9 & 1.4 & 1.7 & 1.2 & 0.6 & 0.5 & 0.4 \\
\hline Motor control (3) & 91.0 & 2.4 & 2.1 & 2.3 & 1.1 & 0.3 & 0.9 & & & & & & & \\
\hline Separations (7) & 78.9 & 11.2 & 5.6 & 1.8 & 1.1 & 0.6 & 0.3 & 0.2 & 0.2 & 0.1 & 0.1 & & & \\
\hline Defiance (8) & 68.3 & 8.5 & 7.9 & 5.4 & 3.5 & 1.8 & 1.4 & 0.8 & 0.8 & 1.0 & 0.4 & 0.2 & & \\
\hline Conduct (15) & 89.3 & 5.8 & 2.5 & 1.1 & 0.6 & 0.4 & 0.1 & 0.1 & 0.1 & 0.1 & & & & \\
\hline
\end{tabular}

${ }^{1}$ Detailed figures: 8.5-9: 1.19\%, 9.5-10: 0.95\%, 10.5-11: 0.74\%, 11.5-12: 0.68\%, 12.5-13: 0.34\%, 13.5-14: 0.41\%, 14.5-15: 0.34\%, >15: 0.33\%.

for problems across the spectrum of child and adolescent psychiatric symptomatology, particularly in the field of learning and attention. The high prevalences of screenpositives for language/communication problems and for poor flexibility are most probably due to the fact that DSM-IV requires only one item to fulfil these criteria, while the threshold for ASD is higher. However, social interaction problems, which are often conceived of as the core autistic trait [19], also showed a high prevalence rate - of over $6 \%$ according to the DSM-IV social interaction criterion for autism, in which at least two symptoms are required.

No module showed evidence of a bimodal distribution, which would suggest that screen positivity represents the extreme tail in normal distributions. This finding suggests that sub-threshold manifestations of disorders should be considered, since cut-offs for screen-positivity probably do not correspond to any non-arbitrary divisions between disorders and "normality". Even autism has recently been conceptualized as a dimensionally distributed problem constellation, in which those subjects who are clearly affected with a clinical disorder represent one extreme tail of an underlying normal distribution $[19,20]$. Parallels can be drawn to the development of the nosology in the field of personality disorders in adults, which has been broadened from clinical descriptions of caseness to definitions of normally distributed traits [21]. The use of a dimensional view in child and adolescent psychiatry is also supported by suggestions that there might be important connections between childhood neurodevelopmental problems and adulthood personality traits [22-24]. From this point of view, the A-TAC has the advantage of exploring the degree to which handicap and suffering are associated with symptoms and features.
Most problem types associated with the traditional "neurodevelopmental" disorders, such as $\mathrm{AD} / \mathrm{HD}$ and $\mathrm{ASD}$, were much more common in boys than in girls. However, there were no striking gender differences in problems associated with learning and compulsiveness. The lack of gender differences in the areas of conduct and eating problems could be due to the small number of screen-positive children in these groups. The overall pattern of gender differences in the study corresponds to the general overrepresentation of clinical neurodevelopmental disorders in boys.

In agreement with the mounting evidence of important overlaps across various child psychiatric disorders [25], we found significant correlations across scores from all the ATAC modules in this general population twin sample. Thus, both in clinical settings and among the general population, the notion of "pure" diagnoses has a weak empirical underpinning, and clinicians and researchers should probably consider a wider complexity of child psychiatric conditions. In his 1991 Emmanuel Miller memorial lecture, Gillberg proposed that autism and ASD were "subclasses among disorders of empathy", overlapping to a considerable extent with other childhood-onset disorders, such as $\mathrm{AD} / \mathrm{HD}$, anorexia nervosa, and OCD [26]. This notion has since come to be strongly supported by empirical data (for a review, see Angold et al., 1999). Like some previous authors, we found that $\mathrm{AD} / \mathrm{HD}$ symptoms were common in ASD high scorers, and tic disorders and/or learning disorder were reported in several other problem groups [13,27,28].

A-TAC symptom scores converged in three factors, which roughly corresponded to problems with (1) hyperactivity, inattention, opposition and conduct, (2) communication and social interaction with learning, executive, and perceptual problems, and (3) compulsiveness with anxiety and 
Table 3. Proportion of Subjects (\%) who are Screen-Positive for a Diagnostic Category (Rows) and Also Fulfil the Definitions for Another (Columns). Spearman Correlation Coefficients ( $\rho)$ Between the Categories are Given Below the Proportions $(\mathbf{n}=\mathbf{2 9 5 7})$

\begin{tabular}{|c|c|c|c|c|c|c|c|c|c|c|}
\hline & $\begin{array}{c}1 \\
\text { AS }\end{array}$ & $\begin{array}{c}5 \\
\text { Tics }\end{array}$ & $\begin{array}{c}6 \\
\text { AD/HD }\end{array}$ & $\begin{array}{c}9 \\
\text { MC }\end{array}$ & $\begin{array}{c}10 \\
\text { Learn }\end{array}$ & $\begin{array}{c}11 \\
\text { Comp }\end{array}$ & $\begin{array}{c}12 \\
\text { Eating }\end{array}$ & $\begin{array}{c}13 \\
\text { Sep }\end{array}$ & $\begin{array}{c}14 \\
\text { Opp }\end{array}$ & $\begin{array}{c}15 \\
\text { Conduct }\end{array}$ \\
\hline 1. Autism spectrum (AS) & & $\begin{array}{l}23.1 \% \\
\rho=0.15\end{array}$ & $\begin{array}{c}76.9 \% \\
\rho=0.43\end{array}$ & $\begin{array}{c}59.0 \% \\
\rho=0.24\end{array}$ & $\begin{array}{l}46.2 \% \\
\rho=0.28\end{array}$ & $\begin{array}{l}30.8 \% \\
\rho=0.21\end{array}$ & $\begin{array}{c}0 \% \\
\rho=0.15\end{array}$ & $\begin{array}{l}13.2 \% \\
\rho=0.25\end{array}$ & $\begin{array}{l}38.5 \% \\
\rho=0.43\end{array}$ & $\begin{array}{c}2.6 \% \\
\rho=0.25\end{array}$ \\
\hline 5. Tics & $16.1 \%$ & & $\begin{array}{l}35.7 \% \\
\rho=0.20\end{array}$ & $\begin{array}{l}21.4 \% \\
\rho=0.14\end{array}$ & $\begin{array}{l}17.9 \% \\
\rho=0.07\end{array}$ & $\begin{array}{l}21.4 \% \\
\rho=0.16\end{array}$ & $\begin{array}{c}0 \% \\
\rho=0.07\end{array}$ & $\begin{array}{c}5.4 \% \\
\rho=0.14\end{array}$ & $\begin{array}{l}25.0 \% \\
\rho=0.20\end{array}$ & $\begin{array}{c}1.8 \% \\
\rho=0.13\end{array}$ \\
\hline 6. AD/HD & $18.3 \%$ & $12.1 \%$ & & $\begin{array}{l}25.9 \% \\
\rho=0.23\end{array}$ & $\begin{array}{l}30.7 \% \\
\rho=0.38\end{array}$ & $\begin{array}{l}11.5 \% \\
\rho=0.15\end{array}$ & $\begin{array}{c}0 \% \\
\rho=0.15\end{array}$ & $\begin{array}{c}6.7 \% \\
\rho=0.29\end{array}$ & $\begin{array}{l}25.5 \% \\
\rho=0.51\end{array}$ & $\begin{array}{c}3.6 \% \\
\rho=0.33\end{array}$ \\
\hline 9. Motor control (MC) & $17.6 \%$ & $9.1 \%$ & $32.6 \%$ & & $\begin{array}{l}27.1 \% \\
\rho=0.24\end{array}$ & $\begin{array}{c}6.0 \% \\
\rho=0.09\end{array}$ & $\begin{array}{c}0 \% \\
\rho=0.10\end{array}$ & $\begin{array}{c}5.3 \% \\
\rho=0.11\end{array}$ & $\begin{array}{l}11.4 \% \\
\rho=0.16\end{array}$ & $\begin{array}{c}0.8 \% \\
\rho=0.11\end{array}$ \\
\hline 10. Learning (Learn) & $8.6 \%$ & $4.8 \%$ & $24.6 \%$ & $17.2 \%$ & & $\begin{array}{c}4.3 \% \\
\rho=0.07\end{array}$ & $\begin{array}{c}0 \% \\
\rho=0.10\end{array}$ & $\begin{array}{c}2.4 \% \\
\rho=0.19\end{array}$ & $\begin{array}{l}10.5 \% \\
\rho=0.23\end{array}$ & $\begin{array}{c}1.0 \% \\
\rho=0.17\end{array}$ \\
\hline 11. Compulsion (Comp) & $21.1 \%$ & $21.1 \%$ & $33.3 \%$ & $14.0 \%$ & $15.8 \%$ & & $\begin{array}{c}3.5 \% \\
\rho=0.10\end{array}$ & $\begin{array}{c}8.9 \% \\
\rho=0.23\end{array}$ & $\begin{array}{l}24.6 \% \\
\rho=0.20\end{array}$ & $\begin{array}{c}3.5 \% \\
\rho=0.11\end{array}$ \\
\hline 12. Eating habits (Eating) & $0 \%$ & $0 \%$ & $0 \%$ & $0 \%$ & $0 \%$ & $66.7 \%$ & & $\begin{array}{c}0 \% \\
\rho=0.13\end{array}$ & $\begin{array}{c}0 \% \\
\rho=0.16\end{array}$ & $\begin{array}{c}0 \% \\
\rho=0.09\end{array}$ \\
\hline 13. Separations (Sep) & $20.0 \%$ & $12.0 \%$ & $44.0 \%$ & $28.0 \%$ & $20.0 \%$ & $20.0 \%$ & $0 \%$ & & $\begin{array}{l}40.0 \% \\
\rho=0.29\end{array}$ & $\begin{array}{c}4.0 \% \\
\rho=0.19\end{array}$ \\
\hline 14. Opposition (Opp) & $21.4 \%$ & $20.0 \%$ & $60.0 \%$ & $21.4 \%$ & $31.4 \%$ & $20.0 \%$ & $0 \%$ & $14.3 \%$ & & $\begin{array}{l}12.9 \% \\
\rho=0.43\end{array}$ \\
\hline 15. Conduct & $10.0 \%$ & $10.0 \%$ & $60.0 \%$ & $10.0 \%$ & $20.0 \%$ & $20.0 \%$ & $0 \%$ & $10.0 \%$ & $90.0 \%$ & \\
\hline
\end{tabular}

All correlations significant at the $\mathrm{p}>0.01$ level.

lack of flexibility. There are obvious parallels between these factors and classic temperament types or dimensions, which often reflect novelty/sensation-seeking, social interaction, and emotionality/neuroticism. Problem constellations that most probably represent neurodevelopmental features, such as motor dyscoordination, perception abnormalities, learning disorders, and tics, fit into the general child and adolescent psychiatric problem picture and correlate not only with problems associated with $\mathrm{AD} / \mathrm{HD}$ and $\mathrm{ASD}$, but also with anxiety, opposition, and compulsiveness. Conduct problems, which have repeatedly been shown to precede adult social maladjustment [29], have also been found to be associated with virtually all aspects of neurodevelopmental and psychiatric problems, a finding that underpins the neuropsychiatric vulnerability of individuals who end up on the "margins of society" [30].

Despite the strong correlations between problem types, a considerable number of children were screen-positive for only one category. This indicates that not only overlapping diagnoses should be accounted for in studies on "comorbidity" or co-existence of problems, but also subclinical traits or problems from other areas that may be encountered in connection with the "main" diagnoses.

Among instruments that are possible to use in large-scale, non-clinical research, the A-TAC is unique in that it (a) indicates caseness for ASD and related disorders, (b) provides dimensional assessments of various types of behaviour and emotional problems in children, and (c) has been validated as a telephone interview. Most interviews, especially
Table 4. Factor Analysis

\begin{tabular}{|l|c|c|c|}
\hline \multicolumn{1}{|c|}{ Module } & Factor 1 & Factor 2 & Factor 3 \\
\hline \hline Conduct & 0.79 & 0.00 & 0.08 \\
\hline Opposition & 0.77 & 0.14 & 0.32 \\
\hline Impulsiveness and Activity & 0.70 & 0.24 & 0.18 \\
\hline Concentration and attention & 0.61 & 0.53 & 0.07 \\
\hline Language & 0.10 & 0.72 & 0.22 \\
\hline Motor control & -0.03 & 0.71 & 0.21 \\
\hline Learning & 0.26 & 0.67 & -0.13 \\
\hline Social interaction & 0.34 & 0.52 & 0.33 \\
\hline Compulsion & 0.08 & -0.02 & 0.76 \\
\hline Flexibility & 0.36 & 0.36 & 0.54 \\
\hline Tics & 0.16 & 0.08 & 0.53 \\
\hline Separations & 0.31 & 0.11 & 0.45 \\
\hline Eating habits & 0.00 & 0.11 & 0.37 \\
\hline
\end{tabular}

those adapted for lay interviewers and large-scale epidemiological research, have been developed based on empirical data from broad assessments of problem types, rather than on the basis of clinical definitions. The Childhood Behaviour Checklist (CBCL) was initially developed according to empirical considerations [31], but has later been adjusted in accordance with DSM-IV categories [32], but several aspects 
of the ASD complex are missing. The Autism Spectrum Screening Questionnaire (ASSQ) [3, 33], the Social Reciprocity Scale (SRS) [19], and the Autism Quotient (AQ) [34, 35], all provide dimensional assessments of autism-related traits and have empirically based cut-off scores, but they do not assess co-existing problem areas and have been validated as paper-and-pencil questionnaires only. In contrast, more elaborate clinical, interview-based, diagnostic schedules, such as the Kiddie-Schedule for Affective Disorders and Schizophrenia (K-SADS) [36] and the Diagnostic Interview for Social and Communication disorders (DISCO) [37], may contribute towards more precise clinical diagnoses but are less useful in non-clinical research because of the amount of time required to complete full interviews. In general, they also focus on specific diagnoses without accounting for dimensionality or the complexity of co-existing problems. Other non-clinician-administered interviews, including the Children's Interview for Psychiatric Syndromes (ChIPS) and the Diagnostic Interview for Children and Adolescents (DICA-R-C) [38, 39], do not cover criteria for ASD, tic disorders, or $\mathrm{AD} / \mathrm{HD}$.

\section{Limitations of the Study}

Obvious limitations are inherent in the non-clinical diagnostics applied and in the use of one informant only. Twins may not be representative of the general population in terms of mental health problems and psychomotor development. However, most empirical studies that have examined this issue have found no or very small differences between twins and singletons [40]. Kendler, for example, found no differences in psychotic and affective disorders among twins as compared to population expectation [41]. The high degree of co-existing problems in this study may to some extent be explained by overall differences in response style, where some parents readily report a large number of problems, and others are "deniers" throughout. It does not seem likely that response style alone could account for most of the variance of the results of the study. Recall bias might have affected the results. However, there were very few significant differences between the nine- and twelve-year-old children, supporting that the A-TAC generally succeeds in assessing symptoms and problems in a lifetime perspective.

\section{ACKNOWLEDGEMENTS}

The Swedish Twin Registry is supported by grants from the Swedish Department of Higher Education, Stockholm, and from AstraZeneca. Professors Gillberg and Anckarsäter had funding from the Swedish Research Council. The collaboration of Mr. Stahlberg was covered by funds from the National Board of Institutional Care to Professor Anckarsäter, and the collaboration of Dr Hansson and $\mathrm{Mr}$ Larson was covered by funds from the Research Council of the Swedish National Alcohol Monopoly to Professor Anckarsäter.

Anita Larsson, Monika Montell, and Agneta Brimse provided excellent secretarial assistance in the writing phase of the project.

\section{REFERENCES}

[1] Gillberg C, Cederlund M, Lamberg K, Zeijlon L. Brief report: "the autism epidemic". The registered prevalence of autism in a Swedish urban area. J Autism Dev Disord 2006; 36(3): 429-35.

[2] Kadesjo B, Gillberg C. The comorbidity of ADHD in the general population of Swedish school-age children. J Child Psychol Psychiatry $2001 ; 42(4)$ : 487-92.

[3] Posserud MB, Lundervold AJ, Gillberg C. Autistic features in a total population of 7-9-year-old children assessed by the ASSQ (Autism Spectrum Screening Questionnaire). J Child Psychol Psychiatry $2006 ; 47(2): 167-75$.

[4] Piven J, Palmer P, Jacobi D, Childress D, Arndt S. Broader autism phenotype: evidence from a family history study of multipleincidence autism families. Am J Psychiatry 1997; 154(2): 185-90.

[5] Baron-Cohen S, Scahill VL, Izaguirre J, Hornsey H, Robertson MM. The prevalence of Gilles de la Tourette syndrome in children and adolescents with autism: a large scale study. Psychol Med 1999; 29(5): 1151-59.

[6] Gillberg C. Perceptual, motor and attentional deficits in Swedish primary school children. Some child psychiatric aspects. J Child Psychol Psychiatry 1983; 24(3): 377-403.

[7] Hattori J, Ogino T, Abiru K, Nakano K, Oka M, Ohtsuka Y. Are pervasive developmental disorders and attention-deficit/hyperactivity disorder distinct disorders? Brain Dev 2006; 28(6): 371-4.

[8] Bejerot S, Nylander L, Lindstrom E. Autistic traits in obsessivecompulsive disorder. Nord J Psychiatry 2001; 55(3): 169-76.

[9] Nilsson EW, Gillberg C, Gillberg IC, Rastam M. Ten-year followup of adolescent-onset anorexia nervosa: personality disorders. J Am Acad Child Adolesc Psychiatry 1999; 38(11): 1389-95.

[10] Siponmaa L, Kristiansson M, Jonson C, Nyden A, Gillberg C. Juvenile and young adult mentally disordered offenders: the role of child neuropsychiatric disorders. J Am Acad Psychiatry Law 2001; 29(4): 420-6.

[11] O'Brien G, Pearson J. Autism and learning disability. Autism 2004; 8(2): 125-40.

[12] Gillberg C, Billstedt E. Autism and Asperger syndrome: coexistence with other clinical disorders. Acta Psychiatr Scand 2000; 102(5): 321-30.

[13] Gillberg C, Gillberg IC, Rasmussen P, et al. Co-existing disorders in ADHD -- implications for diagnosis and intervention. Eur Child Adolesc Psychiatry 2004; 13(Suppl 1): I80-I92.

[14] Kaplan BJ, Dewey DM, Crawford SG, Wilson BN. The term comorbidity is of questionable value in reference to developmental disorders: data and theory. J Learn Disabil 2001; 34 (6): 555-65.

[15] Hansson SL, Svanstrom Rojvall A, Rastam M, Gillberg C, Gillberg IC, Anckarsater H. Psychiatric telephone interview with parents for screening of childhood autism - tics, attention-deficit hyperactivity disorder and other comorbidities (A-TAC): preliminary reliability and validity. Br J Psychiatry 2005; 187(3): 262-7.

[16] Lichtenstein P, Sullivan PF, Cnattingius S, et al. The Swedish Twin Registry in the third millennium: an update. Twin Res Hum Genet 2006; 9(6): 875-82.

[17] Gillberg C, Gillberg IC, Rastam M, Wentz E. The Asperger Syndrome (and high-functioning autism) Diagnostic Interview (ASDI): a preliminary study of a new structured clinical interview. Autism 2001; 5(1): 57-66.

[18] Kadesjo B, Janols LO, Korkman M, et al. The FTF (Five to Fifteen): the development of a parent questionnaire for the assessment of ADHD and comorbid conditions. Eur Child Adolesc Psychiatry 2004; 13(Suppl 3): 3-13.

[19] Constantino JN, Todd RD. Autistic traits in the general population: a twin study. Arch Gen Psychiatry 2003; 60(5): 524-30.

[20] Briskman J, Happe F, Frith U. Exploring the cognitive phenotype of autism: weak "central coherence" in parents and siblings of children with autism: II. Real-life skills and preferences. J Child Psychol Psychiatry 2001; 42(3): 309-16.

[21] Livesley WJ. Commentary on reconceptualizing personality disorder categories using trait dimensions. J Pers 2001; 69(2): 277-86.

[22] Anckarsater H, Stahlberg O, Larson T, et al. The impact of ADHD and autism spectrum disorders on temperament, character, and personality development. Am J Psychiatry 2006; 163(7): 1239-44.

[23] Fischer M, Barkley RA, Smallish L, Fletcher K. Young adult follow-up of hyperactive children: self-reported psychiatric 
disorders, comorbidity, and the role of childhood conduct problems and teen CD. J Abnorm Child Psychol 2002; 30(5): 463-75.

[24] Soderstrom H, Nilsson T, Sjodin AK, Carlstedt A, Forsman A. The childhood-onset neuropsychiatric background to adulthood psychopathic traits and personality disorders. Compr Psychiatry 2005; 46(2): 111-6.

[25] Angold A, Costello EJ, Erkanli A. Comorbidity. J Child Psychol Psychiatry 1999; 40(1): 57-87.

[26] Gillberg C. The Emanuel Miller Memorial Lecture 1991. Autism and autistic-like conditions: subclasses among disorders of empathy. J Child Psychol Psychiatry 1992; 33(5): 813-42.

[27] Comings DE. Clinical and molecular genetics of ADHD and Tourette syndrome. Two related polygenic disorders. Ann N Y Acad Sci 2001; 931: 50-83.

[28] Gillberg C, Soderstrom H. Learning disability. Lancet 2003; 362(9386): 811-21.

[29] Robins L. Deviant children grown up. Baltimore: Williams and Wilkins, 1966

[30] Soderstrom H, Sjodin AK, Carlstedt A, Forsman A. Adult psychopathic personality with childhood-onset hyperactivity and conduct disorder: a central problem constellation in forensic psychiatry. Psychiatry Res 2004; 121(3): 271-80.

[31] Achenbach TM. Manual for the Child Behavior Checklist/4-18 and 1991 Profile. Burlington: University of Vermont, Department of Psychiatry, 1991.

[32] Achenbach TM, Ruffle TM. The Child Behavior Checklist and related forms for assessing behavioral/emotional problems and competencies. Pediatr Rev 2000; 21(8): 265-71.

[33] Ehlers S, Gillberg C. The epidemiology of Asperger syndrome. A total population study. J Child Psychol Psychiatry 1993; 34(8): $1327-50$
[34] Baron-Cohen S, Wheelwright S, Skinner R, Martin J, Clubley E. The autism-spectrum quotient (AQ): evidence from Asperger syndrome/high-functioning autism, males and females, scientists and mathematicians. J Autism Dev Disord 2001; 31(1): 5-17.

[35] Woodbury-Smith MR, Robinson J, Wheelwright S, Baron-Cohen S. Screening adults for Asperger Syndrome using the AQ: a preliminary study of its diagnostic validity in clinical practice. Autism Dev Disord 2005; 35(3): 331-5.

[36] Kaufman J, Birmaher B, Brent D, et al. Schedule for affective disorders and schizophrenia for school-age children-present and lifetime version (K-SADS-PL): initial reliability and validity data. J Am Acad Child Psychol 1997; 36: 980-8

[37] Wing L, Leekam SR, Libby SJ, Gould J, Larcombe M. The Diagnostic Interview for Social and Communication Disorders: back ground, inter-rater reliability and clinical use. J Child Psychol Psychiatry $2002 ; 43(3): 307-25$

[38] Fristad MA, Glickman AR, Verducci JS, Teare M, Weller EB, Weller RA. Study V: Children's Interview for Psychiatric Syndromes (ChIPS): psychometrics in two community samples. J Child Adolesc Psychopharmacol 1998; 8(4): 237-45.

[39] Widom CS, DuMont K, Czaja SJ. A prospective investigation of major depressive disorder and comorbidity in abused and neglected children grown up. Arch Gen Psychiatry 2007; 64(1): 49-56.

[40] Evans DM, Martin NG. The validity of twin studies. GeneScreen 2000; 1(2): 77-9.

[41] Kendler KS, Pedersen NL, Farahmand BY, Persson PG. The treated incidence of psychotic and affective illness in twins compared with population expectation: a study in the Swedish Twin and Psychiatric Registries. J Psychol Med 1996; 26(6): 1135-44.

(C) Anckarsäter et al.; Licensee Bentham Open.

This is an open access article distributed under the terms of the Creative Commons Attribution License (http://creativecommons.org/licenses/by/2.5/), which permits unrestrictive use, distribution, and reproduction in any medium, provided the original work is properly cited. 